Letters addressing topics of current interest or material in RESPIRATORY CARE will be considered for publication. The Editors may accept or decline a letter or edit without changing the author's views. The content of letters reflects the author's opinion or interpretation of information; their publication should not be interpreted as an endorsement by the Journal. Authors of criticized material will have the opportunity to reply in print. No anonymous letters can be published. Letters should be submitted electronically via Manuscript Central. Log onto RESPIRATORY CARE's web site at http://www.RCJournal.com.

\section{Ventilatory Modes. What's in a Name?}

We have read with great interest the paper published by Chatburn et al in RESPIRATORY CARE. ${ }^{1}$ reporting on how familiar healthcare leaders coming from different professions are with some general technical and physiological aspects related to mechanical ventilation. Even if the survey shows a reasonable level of knowledge and agreement between both individuals and professions regarding most of the questions submitted, it must be underlined that the target population consisted mainly of professionals who had prior skills in the field of mechanical ventilation. More than $50 \%$ of responders were respiratory therapists, who often have a substantial level of expertise regarding these issues. Moreover, it is not sure that the same rate of agreement would have been found, even in this specific skilled population, if more detailed questions (ie, as to nomenclature and technical details of ventilator modes proposed by modern ventilators) had been raised. ${ }^{2}$ In fact, as mentioned by the authors, while mechanical ventilation has hugely evolved these last decades, what lags behind is a standard classification or taxonomy able to describe this increasing complexity.

This issue is still more worrying regarding noninvasive ventilation (NIV). Due to growing evidence of NIV's effectiveness in a broad range of indications and increasing availability of user-friendly portable devices, the number of patients receiving NIV at home is continuously increasing, For example, NIV is increasingly applied in different settings, such as critical care units, pulmonary, cardiology ${ }^{3}$ or neurological ${ }^{4}$ departments, pediatrics facilities, weaning centers, sleep labs, in the emergency room, 5,6 in pre-hospital care, ${ }^{7}$ and in general wards. ${ }^{8}$ As a "victim of its own success" NIV has become a generalized practice, and it is not unusual that it may be carried out by nonspecialized healthcare professionals. When NIV was introduced, there were a very limited number of modes and types of ventilators, with very few possible settings. But as NIV devices were submitted to the same market evolution as conventional mechanical ventilation, developments in design and technologies led to the more than 30 models presently available, offering numerous options for settings. ${ }^{2}$

Moreover, there are no marketing regulations for ventilators. This leaves manufacturers free to give different names to identical or very similar ventilators modes and settings and even "create" new modes that correspond frequently only to minor modifications of a previously known mode. This explains why the wide variety of existing terminology describing NIV modes is somewhat confusing; it also explains the lack of a common nomenclature. Clinicians can today be confronted with a given acronym that corresponds to different modes in different devices, and conversely to identical modes that are called differently in different ventilators. Bi-level ventilators, for example, were initially referred to as BiPAPs (a commercial name of the first machine of this type on the market), but use of this term has caused conflict as the manufacturer claimed for copyright. Other terms and acronyms were used such as pressure support ventilation (PSV), IPAP, and EPAP, S/T devices, bilevel pressure assist, CPAP + inspiratory support, and PV with PEEP. This can be a problem in clinical practice, when a nonspecialized physician is confronted with this incomprehensible plethora of names and devices.

In this context, proposing a standardized classification for a better understanding of ventilation and ventilators seems rather logical. But, even if it were possible, this issue involves a high level of complexity regarding critical care ventilators, because of the overabundance and complexity of new (supposed) "intelligent modes" that include complex closed loops and several different targeting algorithms. Furthermore, the classification and terminology applied to intensive care respirators does not necessarily apply to the smaller yet very versatile respirators intended for home use: for these devices it seems easier to provide a standardized classification

As ventilators can be categorized by how they deliver gas flow and how they trigger inspiration and expiration, answers to 3 basic questions may serve as a guide to simplify terminology:
- What is the ventilatory mode (pressure or volume)?

- How is the inspiration triggered (assisted, assisted/controlled, or controlled)?

- How is switching from inspiration to expiration (cycling) managed (flow or timed cycling)?

These 3 categories may facilitate a standardizing of NIV taxonomy and clarify this confusion. Based on these principles, Chopin et al proposed a "physiological" but somewhat complex categorization of ventilatory modes applied to ICU ventilators. ${ }^{9}$ Our group proposes a more pragmatic and ergonomic approach of this classification, applicable to fewer and more simple modes commonly used to provide NIV by using portable devices (Table 1).

Even if there is probably no perfect nomenclature, such an attempt at standardization could provide the basis for a large consensus aiming to achieve a more comprehensive approach to NIV. This may encourage manufacturers to privilege simplicity in their nomenclature instead of originality and confusion. The goal? To make NIV management easier in clinical practice.

Claudio Rabec MD

Service de Pneumologie et Réanimation Respiratoire Centre Hospitalier et Universitaire de Dijon Dijon, France

Bruno Langevin MD

Service de Réanimation Médicale Centre Hospitalier Alès Alès, France

Daniel Rodenstein MD PhD

Service de Pneumologie Cliniques Universitaires Saint Luc Université Catholique de Louvain Bruxelles, Belgium

Christophe Perrin MD Service de Pneumologie Centre Hospitalier Cannes Cannes, France

Patrick Leger MD

Service de Pneumologie Centre Hospitalier Universitaire Lyon Sud Lyon, France 
Table 1. "Physiological" Proposed Classification of Noninvasive Ventilation Current Modes

\begin{tabular}{|c|c|}
\hline Usual Appellations* & "Physiological" Nomenclature \\
\hline Volume-controlled ventilation (VCV) & V-C-T \\
\hline Volume assisted/controlled ventilation & $\mathrm{V}-\mathrm{A} / \mathrm{C}-\mathrm{T}$ \\
\hline $\begin{array}{l}\text { Pressure-controlled ventilation, PCV, T mode } \\
\text { (in bi-level devices) }\end{array}$ & P-C-T \\
\hline $\begin{array}{l}\text { Pressure assisted ventilation (PSV, pressure support } \\
\text { ventilation (PSV), spontaneous (S) mode } \\
\text { (in bi-level devices) }\end{array}$ & $\mathrm{P}-\mathrm{A}-\mathrm{V}$ \\
\hline $\begin{array}{l}\text { Pressure assisted ventilation }+ \text { positive end expiratory } \\
\text { pressure (PEEP) PSV + PEEP, pressure support }+ \\
\text { PEEP, CPAP + inspiratory support, S mode } \\
\text { (in bi-level devices) }\end{array}$ & P-A-V (EPAP) \\
\hline Pressure assisted /controlled ventilation (PAC) & $\mathrm{P}-\mathrm{A} / \mathrm{C}-\mathrm{T}$ \\
\hline Pressure assisted/controlled ventilation (PAC) + PEEP & P-A/C-T (EPAP) \\
\hline $\begin{array}{l}\text { Spontaneous/timed mode (ST), IPAP/EPAP } \\
\text { (in bi-level devices), }\end{array}$ & P-A- $\dot{\mathrm{V}}(\mathrm{EPAP} / \mathrm{f})$ \\
\hline PACV with volume targeting & $\mathrm{P}-\mathrm{A} / \mathrm{C}-\mathrm{T}\left(\mathrm{V}_{\mathrm{T}}\right)$ \\
\hline $\begin{array}{l}\text { ST mode with volume targeting, AVAPS, IVAPS, } \\
\text { volume assured, PS }+ \text { PEEP }+V_{T}\end{array}$ & P-A-V்(EPAP/f/ V $\left.{ }_{T}\right)$ \\
\hline $\begin{array}{l}\text { * Usual appellations correspond to the names devised by the manufacturers } \\
\text { nomenclature the first character indicates ventilatory modality ( } \mathrm{P} \text { or } \mathrm{V}) \text {, the } \\
\mathrm{A} / \mathrm{C}=\text { assisted/controlled, } \mathrm{C}=\text { controlled), and third the mode of switchin } \\
\text { cycling). } \\
\text { IPAP }=\text { inspiratory positive airway pressure } \\
\text { EPAP }=\text { expiratory positive airway pressure } \\
\text { AVAPS = average volume assured pressure support } \\
\text { IVAPS = intelligent volume assured pressure support } \\
\mathrm{V}_{\mathrm{T}}=\text { tidal volume }\end{array}$ & $\begin{array}{l}\text { tality. In the proposed "physiological" } \\
\text { the inspiration is triggered }(\mathrm{A}=\text { assisted, } \\
\text { ation to expiration }(\mathrm{V}=\text { flow, } \mathrm{T}=\text { timed }\end{array}$ \\
\hline
\end{tabular}

Jean-Louis Pepin MD PhD

Pole Rééducation et Physiologie et

Laboratoire Hôpitaux Publique

Institut National de la Santé et de la

Recherche Médicale

Université Joseph Fourier

Grenoble, France

Jean Paul Janssens MD PhD

Service de Pneumologie

Hôpitaux Universitaires de Genève

Geneva, Switzerland

Jésus Gonzalez-Bermejo MD

Service de Pneumologie et

Réanimation Respiratoire

Hôpital de la Pitié-Salpêtrière

Paris, France

\section{On behalf of the SomnoNIV Group}

The authors have disclosed no conflicts of interest.

\section{REFERENCES}

1. Chatburn RL, Volsko TA, Hazy J, Harris LN, Sanders S. Determining the basis for a taxonomy of mechanical ventilation. Respir Care 2012;57(4):514-524.
2. Gonzalez-Bermejo J, Laplanche V, Husseini FE, Duguet A, Derenne JP, Similowski T. Evaluation of the user-friendliness of 11 home mechanical ventilators. Eur Respir J 2006;27(6):1236-1243.

3. Vital FM, Saconato H, Ladeira MT, Sen A, Hawkes CA, Soares B, et al. Non-invasive positive pressure ventilation (CPAP or bilevel NPPV) for cardiogenic pulmonary edema. Cochrane Database Syst Rev 2008; (3):CD005351.

4. Atkeson AD, RoyChoudhury A, Harrington-Moroney G, Shah B, Mitsumoto H, Basner RC. Patient-ventilator asynchrony with nocturnal noninvasive ventilation in ALS. Neurology 2011;77(6):549-555.

5. Cabrini L, Antonelli M, Savoia G, Landriscina M. Non-invasive ventilation outside of the intensive care unit: an Italian survey. Minerva Anestesiol 2011;77(3): 313-22.

6. Davey M. Theme: non-invasive positive pressure ventilation (NiPPV) in the ED. Emerg Med J 2010;27(12):903, 966.

7. Taylor DM, Bernard SA, Masci K, MacBean CE, Kennedy MP, Zalstein S. Prehospital noninvasive ventilation: a viable treatment option in the urban setting. Prehosp Emerg Care 2008;12(1):42-55.

8. Plant PK, Owen JL, Elliott MW. Early use of non-invasive ventilation for acute exac- erbations of chronic obstructive pulmonary disease on general respiratory wards: a multicentre randomised controlled trial. Lancet 2000;355(9219):1931-1935.

9. Chopin C, Chambrin M. An attempt to classify the current positive airway pressure modes of mechanical ventilation. Réanimation Urgences 1998;7:87-99. Article in French.

The authors respond:

Rabec et al have supported the concerns mentioned in our paper, ${ }^{1}$ noting that, "while mechanical ventilation has hugely evolved these last decades, what lags behind is a standard classification or taxonomy able to describe this increasing complexity." In addition, they have pointed out the further concern that confusion about modes may be an even greater problem regarding home care ventilation, and particularly noninvasive ventilation "when a non-specialized physician is confronted with this incomprehensible plethora of names and devices." Indeed, they reference a paper that lists no less than 24 unique mode names on 11 different home care ventilators.

Having studied and written about this subject for over 20 years, and having served as a consultant to committees from the International Standards Organization and the IHE (Integrating the Healthcare Enterprise, www.ihe.net), I have come to appreciate the complexity of addressing this problem. The solution requires a level of treatment well above simply creating an intuitively pleasing nomenclature, such as the "physiological nomenclature" suggested by Rabec et al. The solution is to create a formal taxonomy.

Taxonomy is the science of classification. The most common taxonomies have historically been those applied to plants and animals, in the form of class, family, genus, and species. However, the rapid growth of the World Wide Web, and more specifically, the Semantic Web, has created an intense need for organized search strategies that are based on taxonomies. One well known example is the Taxonomy of Educational Objectives, also known as Bloom's Taxonomy. A taxonomy is typically a hierarchical classification or categorization system. Anyone who has ever been to the Web site www.Amazon.com has used a taxonomy. The menu along the left hand side of Amazon's Web page is an expandable outline. For example, if you select "books" from 


\section{LETTERS TO THE EDITOR}

the list of products sold, you will get another list lower down on the hierarchy, including different types of books (eg, audio books, business and investing, children's books, cookbooks, et cetera). Clicking any of these selections brings you to an even deeper level of the taxonomy. Another very good example of a visual display of a taxonomy can be seen at http://www. accessinn.com:8081/PerfectSearch/ navtree/index.html. At this Web site the explicit collapsible levels of the taxonomy's hierarchy are clearly visible. This latter example is more appropriately called a thesaurus. Most of us are familiar with a thesaurus as a kind of dictionary, such as Roget's Thesaurus, which contains synonyms for each entry. A dictionary-type thesaurus includes all the associated terms that could be used in place of the term entry in various contexts. In contrast, a thesaurus used for information retrieval is designed for use in all contexts within the domain of content covered, regardless of any specific term usage or document. A thesaurus of this type, therefore, is a more structured type of controlled vocabulary that provides information about each term and its relationships to other terms within the same thesaurus. ${ }^{2}$ National and international standards that provide guidance for creating such thesauri include:

- International Organization for Standardization (www.iso.org/iso/iso_catalogue. htm)

- ISO 2788 (1986): Guidelines for the Establishment and Development of Monolingual Thesauri

- ISO 5964 (1985): Guidelines for the Establishment and Development of Multilingual Thesauri

- ISO 2788 and 5964 were replaced in 2011 by ISO 25964: Thesauri and Interoperability With Other Vocabularies

- American National Standards Institute (ANSI) and National Information Standards Organization (NISO) (www.niso. org/kst/reports/standards)

- ANSI/NISOZ39.19(2005): Guidelines for the Construction, Format, and Management of Monolingual Controlled Vocabularies

- British Standards Institution (www.bsigroup.com)

- BS 8723-1 (2005): Structured Vocabularies for Information Retrieval: Definitions, Symbols, and Abbreviations
- BS 8723-2 (2005): Structured Vocabularies for Information Retrieval: Thesauri

These standards describe 3 types of relationships in a thesaurus: hierarchical (broader term/narrower term), associative (related term), and equivalence (use/used for). For simplicity, I will include the thesaurus in the term "taxonomy."

Taxonomies are not generally created by committee. Rather, a trained taxonomist constructs them from several key components after becoming sufficiently familiar with the content of the subject domain (usually with input from end users). In my case, I started as a domain expert who had to learn about taxonomy: what has been called an "accidental taxonomist." 2 Either way, the first component to create is a "controlled vocabulary," which is a glossary of predefined terms. Choosing appropriate terms is difficult, because there are usually many ways to define key concepts. Priority must be given to specificity and logical consistency throughout the domain of application. The second component, created using the vocabulary, is the hierarchical structure of the taxonomy. There are many logical systems that may work, so priority must be given to the one that is most useful and most easily implemented among all groups of stakeholders. The number of levels in the hierarchy is important; too few and you lose the ability to discriminate among items; too many and you lose the advantage of grouping. Creating 3 to 5 levels seems to be about right, and this may be related to the human capacity to store and process only about 4 variables at a time. ${ }^{3}$ Many taxonomies, created at great expense, have failed because of insufficient planning of vocabularies and hierarchies. The third component is the associative and equivalence relationships required to create the finished product. A well constructed taxonomy offers these advantages ${ }^{4}$ :

- Description

- Reduction of Complexity

- Identification of Similarities

- Identification of Differences

- Comparison of Types

- Explanation of Relationships

These benefits justify the resources required to create and maintain a taxonomy.
According to Hedden, ${ }^{2}$ "A taxonomy is never finished. As soon as it is implemented, it undergoes testing and revision, and continued use will dictate further enhancements. All taxonomies require ongoing maintenance, and many taxonomies also undergo more significant revisions or restructuring over time."

Taxonomies serve one of 3 practical functions, particularly important in this age of the electronic medical record: indexing support; retrieval support; and navigation support. Thus, the taxonomy's initial purpose is to serve the people doing the indexing, although a second, equally important purpose is to serve the end users. ${ }^{2}$ In the context of mechanical ventilation, the "indexers" are primarily the engineers and marketing people working for ventilator manufacturing companies, who must write the ventilator operators' manuals. Although manufacturers are responsible for creating the chaos related to modes, they are also in the best position to fix the problem. There is no need for manufacturers to stop creating new names for modes, but they must all agree on a standard description of the mode (ie, how it is classified relative to other modes), and they must use the same vocabulary to explain how it performs. Without this, both patient care and device sales will continue to be at risk. Until manufacturers have reached such a level of consensus, however, the responsibility for indexing modes of ventilation must fall to the members of the other stake-holder groups (ie, clinicians, educators, and researchers).

Recognizing the need for a formal taxonomy of modes of mechanical ventilation was the underlying motive of our paper. ${ }^{1}$ What Rabec et al may not have noticed (due to recent publication) is the book chapter ${ }^{5}$ and paper $^{6}$ from our group demonstrating how the survey questions of our first paper are developed into a classification system. The first step is to expand the 10 questions from the survey into a set of maxims that, when combined, form the theoretical basis of a taxonomy for modes of ventilation 5 :

1. A breath is one cycle of positive flow (inspiration) and negative flow (expiration). The purpose of a ventilator is to assist breathing. Therefore, the logical start of a taxonomy is to define a breath. Breaths are defined such that during mechanical ventilation, small artificial breaths may be superimposed on large natural ones or vice versa. 
2. A breath is assisted if pressure rises above baseline during inspiration or falls during expiration. A ventilator assists breathing by doing some portion of the work of breathing. This occurs by delivering volume under pressure.

3. A ventilator assists breathing using either pressure control $(P C)$ or volume control $(V C)$. The equation of motion for the respiratory system is the fundamental model for understanding patient-ventilator interaction and hence modes of ventilation. The equation is an expression of the idea that only one variable can be predetermined at a time: pressure or volume (flow control is ignored for simplicity and for historical reasons, and because controlling flow directly will indirectly control volume and vice versa).

4. Breaths are classified according to the criteria that trigger (start) and cycle (stop) inspiration. A ventilator must know when to start and stop flow delivery for a given breath. Because starting and stopping inspiratory flow are critical events in synchronizing patient-ventilator interaction, and because they involve uniquely different operator-influenced factors, they are distinguished by giving them different names.

5. Trigger and cycle events can be either patient or machine initiated. A major design consideration in creating modes is the ability to synchronize breath delivery with patient demand and at the same time to guarantee breath delivery if the patient is apneic. Therefore, understanding patient-ventilator interaction means understanding the difference between machine and patient trigger and cycle events.

6. Breaths are classified as spontaneous or mandatory, based on both the trigger and cycle events. A spontaneous breath arises without apparent external cause. Thus it is patient triggered and patient cycled. Any machine involvement in triggering or cycling leads to a mandatory breath. Note that the definition of a spontaneous breath is independent of the definition of an assisted breath, and applies to but does not require the application of a mechanical ventilator. Consistent with common usage, natural breathing is spontaneous.

7. Ventilators deliver only 3 basic breath sequences: continuous mandatory ventilation $(C M V)$, intermittent mandatory ventilation (IMV), and continuous spontaneous ventilation $(C S V)$. The 2 breath classifications logically lead to 3 possible breath sequences that a mode can deliver: CSV im- plies all spontaneous breaths, IMV allows spontaneous breaths to occur between mandatory breaths, and CMV does not.

8. There are only 5 basic ventilatory patterns: $V C-C M V, V C-I M V, P C-C M V, P C$ $I M V$, and $P C-C S V$. All modes can be categorized by these 5 patterns. This provides enough practical detail about a mode for most clinical purposes.

9. Within each ventilatory pattern there are several variations that can be distinguished by their targeting scheme(s). When comparing modes or evaluating the capability of a ventilator, more detail is required than just the ventilatory pattern. Modes with the same ventilatory pattern can be distinguished by describing the targeting schemes they use. There are at present only 7 basic targeting schemes: set-point, dual, servo, bio-variable, adaptive, optimal, and intelligent, which have been described in detail previously.

10. A mode of ventilation is classified according to its control variable, breath sequence, and targeting scheme(s). A practical taxonomy of ventilatory modes is based on just 4 levels of detail: the control variable (pressure or volume), the breath sequence (CMV, IMV, or CSV), and the targeting scheme used for primary breaths (CMV and CSV), and, if applicable, secondary breaths (IMV). This structure is reminiscent of the taxonomy of biological organisms, which comprises order, family, genus, and species. Modes in the same "species" can be further differentiated by describing their "species variety" in term of their phase variables (ie, trigger, and cycle variables plus the within- and betweenbreath targets and control algorithms). The advantage of such a hierarchical structure is that a mode can be described in any level of detail that is required. For example, we can say that a patient was in volume control during surgery but changed to pressure control during recovery, or that he was changed from PC-CMV to PC-CSV for a spontaneous breathing trial, or that Pressure Support is PC-CSV with set-point targeting, whereas Volume Support is PC-CSV with adaptive targeting.

One thing I want to emphasize is that the legacy meaning of the words "assist" and "control" must be abandoned in the formation of a new taxonomy of modes. The meaning and importance of these words have evolved radically since they were coined by anesthesiologists using the first ventilators over 60 years ago. The problem is that the focus of their meanings has shifted subtly from patient physiology to machine function. A prime example is the use of the term "assist/control." This term focuses on the patient's neurological control of breathing and refers to a mode in which the ventilator may either "control" the breathing pattern by triggering inspiration as a substitute for the patient's own neurological control, or "assist" the patient's inspiratory effort after he/she has triggered inspiration. These definitions date back to a time when ventilator capabilities were very primitive by today's standards.

Ventilators have evolved over at least 5 generations in the span of a single human generation. As a result, many people who have been in the field for a long time (or their students) cling to the older, patientcentric view of the word "control" and thus fail to appreciate the implications and utility of the machine-centric view. Manufacturers feel compelled to perpetuate this inertia because many of these same people make the purchasing decisions. The result is that the term "assist/control" continues to be associated with mode selection on new ventilators, even though the meaning of the term has changed from its historical roots to the point of virtual uselessness. Originally, assist/control meant volume-controlled continuous mandatory ventilation (CMV). Now it can also refer to pressure control (especially in the pediatric literature).

In addition to forming the basis for a taxonomy, the 10 constructs listed above can be used as the basis of a complete teaching system for ventilator technology (ie, how ventilators work as opposed to how they are used). Each one can be expanded to perhaps a week's worth of didactic instruction and laboratory demonstrations. These constructs have been designed to move progressively from simple to complex ideas while supplying a context for the key definitions in a controlled vocabulary. They are uniquely suited to instruction using Bloom's "learning for mastery" model, ${ }^{8}$ which has proven an effective learning theory for medical education. $^{9}$

To facilitate the implementation of a taxonomy based on control variables, breath sequences and targeting schemes (ie, for "indexing" or "tagging" modes), I have created 4 tools. The first tool is an abbreviated controlled vocabulary for mechanical ventilation (which appears at the end of this letter). I have included only those terms necessary to understand and 


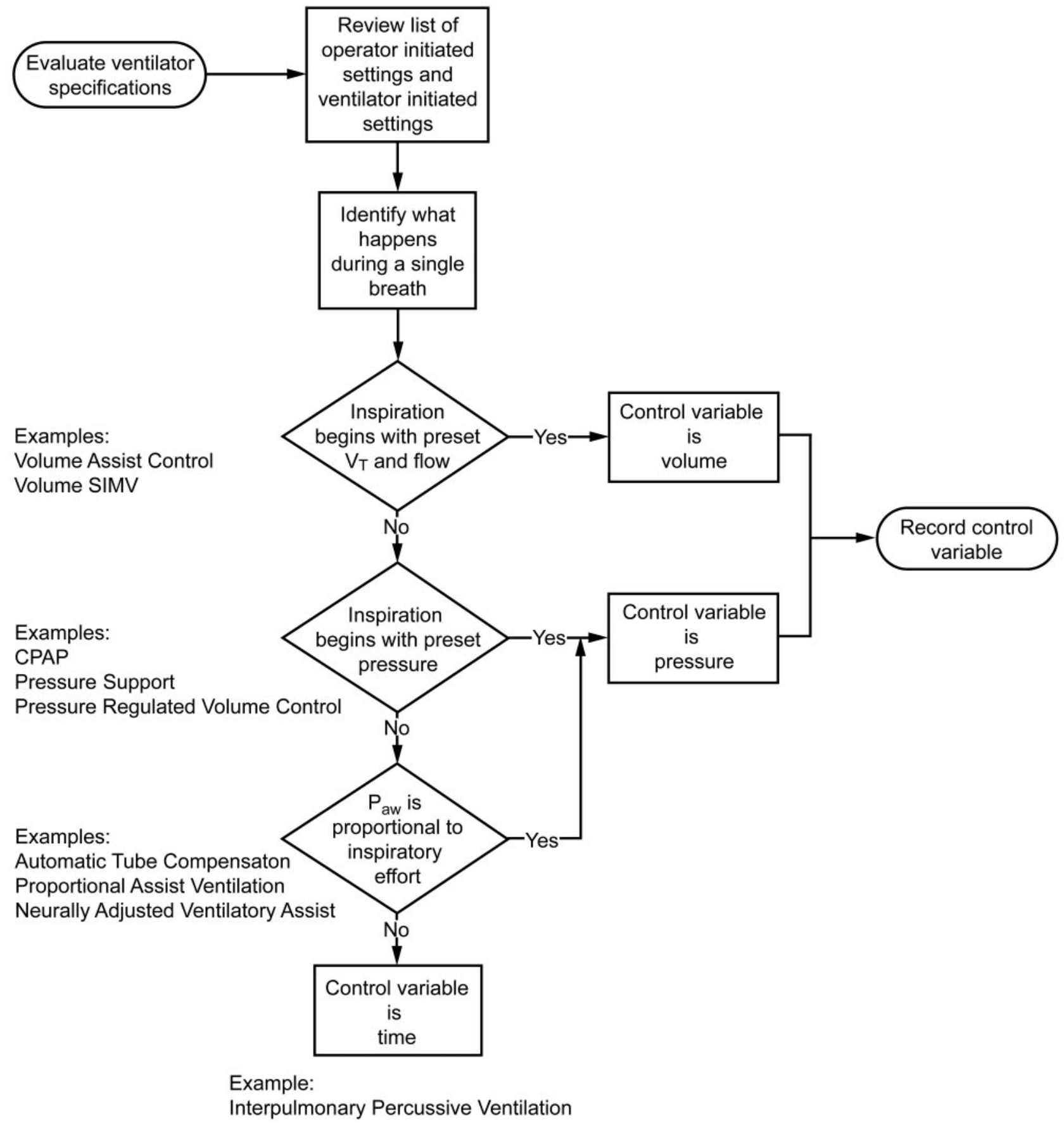

Fig. 1. Algorithm for determining the control variable when classifying a mode. SIMV = synchronized intermittent mandatory ventilation. (With permission from Mandu Press.)

use the taxonomy, but many more could be added for clarity.

Figure 1 shows the second tool: an algorithm for identifying the control variable. Figure 2 shows the third tool: an algorithm for identifying the breath sequence. Figure 3 shows the fourth tool, which provides the information necessary to identify the target- ing schemes used in the design of a mode of ventilation.

To demonstrate the use of these tools, let's classify 4 modes used for noninvasive ventilation. The simplest example is the mode named Pressure Assist/Control. Inspiratory pressure is preset, so the control variable is pressure (see Fig. 1). Every breath is time cycled, so every breath is mandatory (inspiration is machine triggered and/or machine cycled, see the controlled vocabulary and Fig. 2), so the breaths sequence is continuous mandatory ventilation (CMV). Finally, the operator (rather than the ventilator) presets the parameters of the pressure waveform, so the targeting scheme is set- 


\section{LETTERS TO THE EDITOR}

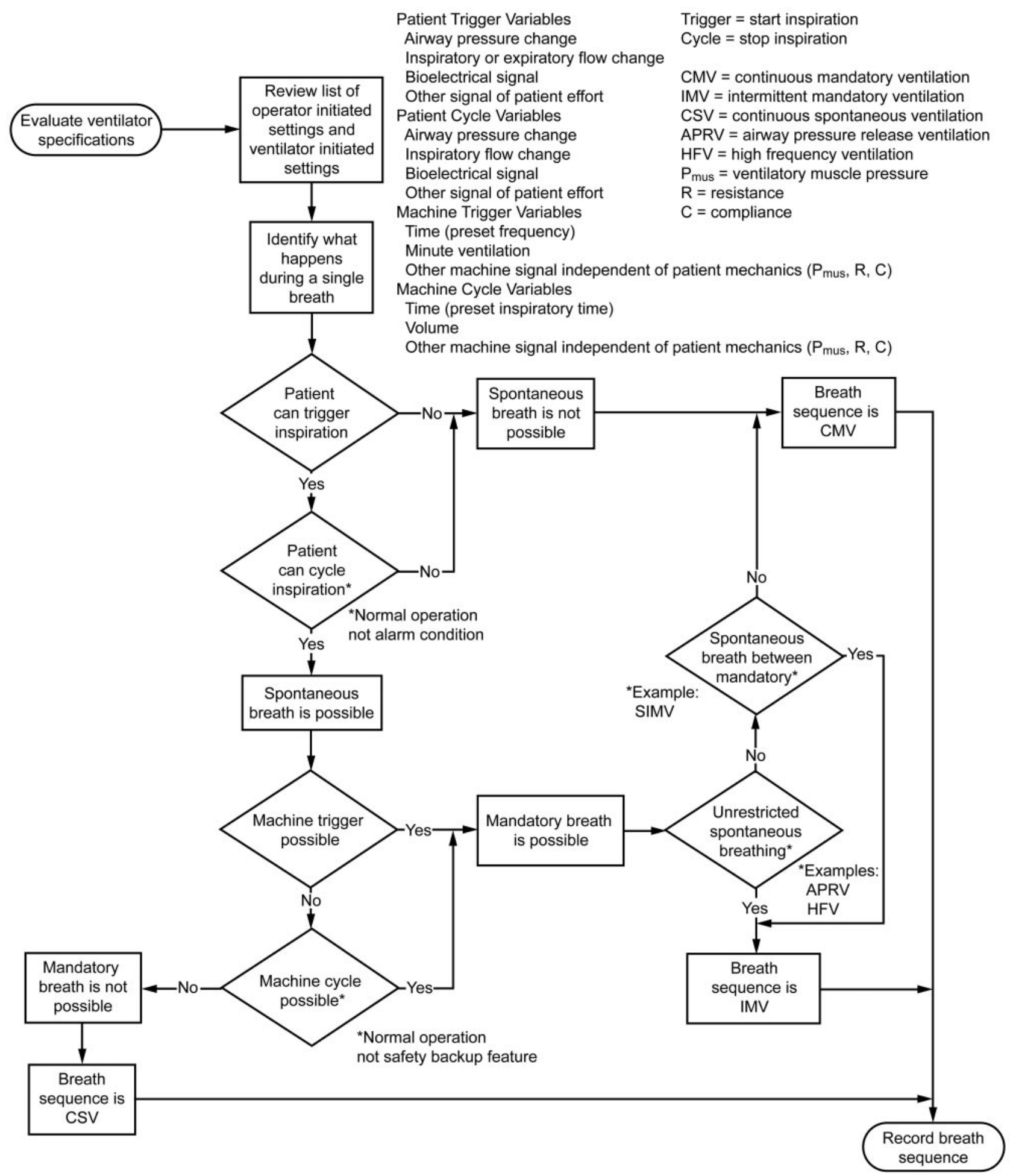

Fig. 2. Algorithm for determining the breath sequence when classifying a mode. SIMV = synchronized intermittent mandatory ventilation. (With permission from Mandu Press.)

point (see the controlled vocabulary and Fig. 3). ${ }^{7}$ The mode is thus classified as pressure control continuous mandatory ventilation with set-point targeting (PC-CMVs).
Now let's classify a little more complex mode, named Average Volume Assured Pressure Support. Again, inspiratory pressure for a given breath is preset, so the con- trol variable is pressure. All breaths are patient triggered and flow cycled (also known as a "Pressure Support" breath). Flow cycling is a function of patient effort and re- 
Identification of Control Variables and Targeting Schemes

\begin{tabular}{|c|c|c|c|c|c|c|c|c|}
\hline \multirow[b]{2}{*}{ \# } & \multirow{2}{*}{$\begin{array}{l}\text { Control } \\
\text { Variable }\end{array}$} & \multirow{2}{*}{$\begin{array}{l}\text { Target } \\
\text { Scheme }\end{array}$} & \multirow[b]{2}{*}{ Explanation } & \multirow[b]{2}{*}{ Example Mode Name } & \multicolumn{3}{|c|}{ Predetermined Inputs } & Ventilator Output \\
\hline & & & & & WB Target & Cycle & BB Target & mpedance $\uparrow$ Impedance \\
\hline 1 & $\mathrm{P}$ & Set-point & $\begin{array}{l}\text { Peak airway pressure is } \\
\text { independent of impedance }\end{array}$ & PC SIMV & $P$ & T & & \\
\hline 2 & P & Set-point & $\begin{array}{l}\text { Peak airway pressure is } \\
\text { independent of impedance }\end{array}$ & Pressure support & $\mathbf{P}$ & $\mathrm{F}$ & & \\
\hline 3 & $P$ & Set-point & $\begin{array}{l}\text { Peak airway pressure is } \\
\text { independent of impedance }\end{array}$ & Automatic resuscitatior & $\mathrm{F}$ & $P$ & & \\
\hline 4 & V & Set-point & $\begin{array}{l}\text { Tidal volume is } \\
\text { independent of impedence }\end{array}$ & $\mathrm{VCA} A \mathrm{C}$ & $\mathrm{F}$ & T & & \\
\hline 5 & P & Dual P-F & $\begin{array}{l}\text { Same as \#1 if secondary } \\
\text { target is not activated }\end{array}$ & VAPS & PF & v & & \\
\hline 6 & V & Dual F-P & $\begin{array}{l}\text { Same as \#4 if secondary } \\
\text { target is not activated }\end{array}$ & CMV + Pressure Limited & $F, P$ & v & & \\
\hline \multirow[t]{2}{*}{7} & P & Servo & $\begin{array}{l}\text { Pressure is automatically } \\
\text { proportional to inspiratory effort } \\
\text { Effort is represented by patient: }\end{array}$ & & $\begin{array}{l}\text { Percent } \\
\text { Support }\end{array}$ & $\mathrm{F}$ & & \\
\hline & & & $\begin{array}{r}\text { flow } \\
\text { volume and flow }\end{array}$ & $\begin{array}{l}\text { ATC } \\
\text { PAV+ }\end{array}$ & & & & \\
\hline 8 & $P$ & Servo & $\begin{array}{l}\text { Pressure is automatically } \\
\text { proportional to inspiratory effort } \\
\text { represented by diaphragm EMG }\end{array}$ & NAVA & $\frac{\mathrm{cm} \mathrm{H}_{2} \mathrm{O}}{\mu \mathrm{v}}$ & NA & & \\
\hline 9 & P & Bio-variable & $\begin{array}{l}\text { Pressure is automatically } \\
\text { adjusted randomly using } \\
\text { preset mean and \%variability }\end{array}$ & Variable Pressure Support & $P$ & $\mathrm{~F}$ & $\begin{array}{l}\% \text { variability } \\
\text { of Pressure }\end{array}$ & \\
\hline 10 & P & Adaptive & $\begin{array}{l}\text { Same as \#1 within a breath plus } \\
\text { volume target between breaths }\end{array}$ & PRVC & NA & T & Volume & \\
\hline 11 & P & Optimal & $\begin{array}{l}\text { Same as \#10 plus algorithm to } \\
\text { minimize inspiratory work rate }\end{array}$ & ASV & NA & $\mathrm{F}$ & $\begin{array}{l}\% \dot{V}_{E} \\
\text { Frequency } \\
\text { Volume }\end{array}$ & \\
\hline 12 & P & Intelligent & $\begin{array}{l}\text { Same as \#10 plus volume, } \mathrm{PcO}_{2} \\
\text { and frequency targets using } \\
\text { artificial intelligence algorithms }\end{array}$ & SmartCare/PS & NA & NA & $\begin{array}{l}\text { Frequency } \\
\text { Volume } \\
\mathrm{PETCO}_{2}\end{array}$ & \\
\hline \multicolumn{5}{|c|}{$\mathrm{P}=$ pressure, $\mathrm{V}=$ volume, $\mathrm{F}=$ flow, $\mathrm{T}=$ time, $\mathrm{R}=$ resistance, $\mathrm{E}=$ elastance } & \multicolumn{4}{|c|}{$\begin{array}{l}\text { Low impedance }=\text { low resistance and/or elastance } \\
\text { High impedance }=\text { high resistance and/or elastance }\end{array}$} \\
\hline $\begin{array}{l}\dot{V}_{E} \\
\text { WB } \\
\text { BB }\end{array}$ & $\begin{array}{l}\text { minute vo } \\
\text { arget }=\text { wit } \\
\text { arget }=\text { bet }\end{array}$ & $\begin{array}{l}\text { olume } \quad E_{c} \\
\text { thin-breath pr } \\
\text { tween-breath }\end{array}$ & $\begin{array}{l}\text { di = electrical activity of diaphragm } \\
\text { reset parameters of the pressure, } \\
\text { targets modify WB targets or over }\end{array}$ & $\begin{array}{l}\text { volume, or flow waveform } \\
\text { rall ventilatory pattern }\end{array}$ & High & mpedan & ce $=$ high resi & stance and/or elastance \\
\hline
\end{tabular}

Fig. 3. Rubric for determining the targeting schemes when classifying a mode. See controlled vocabulary for terms. (With permission from Mandu Press.)

spiratory system mechanics, and hence is considered patient cycling. Thus, spontaneous breaths (patient triggered and patient cycled inspiration; see the controlled vocabulary) are possible. However, if the patient does not trigger breaths above the preset rate, the ventilator will trigger a breath. A machine triggered breath is defined as a mandatory breath. Therefore, spontaneous breaths may occur between mandatory breaths, and the breath sequence is classified as intermittent mandatory ventilation (IMV). Finally, the inspiratory pressure is automatically adjusted between breaths by the ventilator, to achieve an average tidal volume equal to the operator set target, which is an example of adaptive targeting. ${ }^{7}$ The mode is thus classified as pressure control intermittent mandatory ventilation with adaptive targeting for both mandatory and spontaneous breaths (PC-IMVa,a).

Having mentioned Pressure Support (simply called "Spontaneous" mode on some ventilators), we should also classify this common mode. Inspiratory pressure is preset, so the control variable is pressure. Ev- ery breath is spontaneous (ie, patient triggered and cycled), so the breath sequence is continuous spontaneous ventilation. Finally, the operator sets a fixed inspiratory pressure, so the targeting scheme is set-point. ${ }^{7}$ Thus the mode is classified as pressure control continuous spontaneous ventilation with set-point targeting (PC-CSVs).

The fourth example is a mode named Proportional Pressure Ventilation (another name for Proportional Assist Ventilation, which was originally developed as an invasive mode). Inspiratory pressure is prede- 
termined, but not to a fixed value. Rather, it is constrained to be proportional to patient effort, according to the equation of motion for the respiratory system. ${ }^{7}$ Hence, the control variable is pressure. Every inspiration is patient triggered and patient cycled (we ignore the backup mode that is activated in the case of apnea), so the breath sequence is continuous spontaneous ventilation (CSV). Finally, the targeting scheme that makes inspiratory pressure proportional to inspiratory effort is called servo. ${ }^{7}$ Thus, the mode is classified as pressure control continuous spontaneous ventilation with servo targeting (PC-CSVr).

This mode taxonomy is equally useful for invasive modes. Indeed, the taxonomy for classifying the technical capability of a ventilator is independent of the ventilatorpatient interface (ie, artificial airway vs mask). For example, consider the most commonly used mode in ICUs: "Volume Assist/Control." For this mode, both inspiratory volume and flow are preset, so the control variable is volume (see Fig. 1). Every breath is volume cycled, which is a form of machine cycling (see the controlled vocabulary). Any breath in which inspiration is machine cycled is classified as a mandatory breath. Hence, the breath sequence is continuous mandatory ventilation (see Fig. 2). Finally, the operator sets the parameters of the volume and flow waveforms, so the targeting scheme is set-point (see Fig. 3). Thus, the mode is classified as pressure control continuous mandatory ventilation with set-point targeting.

If carefully applied, the taxonomy has the power to clarify and unmask hidden complexity in a mode that has a cryptic name. Take, for example, the mode called $\mathrm{CMV}+$ AutoFlow on the Dräger Evita XL ventilator. While "CMV" on this ventilator is the same as "Volume Assist/Control" described above, adding the "AutoFlow" feature changes it to a completely different mode. For $\mathrm{CMV}+$ AutoFlow, the operator sets a target tidal volume but not inspiratory flow. Indeed, inspiratory flow is highly variable, because the ventilator actually sets the inspiratory pressure within a breath. Thus, the control variable, according to the equation of motion, is pressure (see Fig. 1). Every inspiration is time cycled, so every breath is mandatory and the breath sequence is continuous mandatory ventilation (CMV). The ventilator adjusts the inspiratory pressure between breaths to achieve an average tidal volume equal to the preset value, using an adaptive targeting scheme. ${ }^{7}$ Thus, the mode is classified as pressure control continuous mandatory ventilation with adaptive targeting (PC-CMVa).

On the other hand, the taxonomy can unmask the complexity in an apparently simple mode. A good example is the mode named simply "Volume Control" on the Maquet Servo-i ventilator. As with Volume Assist/Control on other ventilators, the operator presets both inspiratory volume and flow (inspiratory flow is set indirectly by tidal volume and inspiratory time settings). From Figure 1 we see that this indicates volume control, as expected. However, a careful reading of the operator's manual indicates that whether a breath is mandatory or spontaneous depends on the level of patient inspiratory effort. This is because the ventilator uses dual targeting (see the controlled vocabulary and Fig. 3). ${ }^{7}$ If the patient makes no inspiratory effort, inspiration is machine triggered (by a preset ventilatory frequency) and time cycled (by a preset inspiratory time). Hence, such a breath is classified as mandatory. If the patient makes a moderate inspiratory effort, enough to make inspiratory pressure fall $3 \mathrm{~cm} \mathrm{H}_{2} \mathrm{O}$, the ventilator switches from volume control to pressure control and delivers as much flow as the patient demands. If the inspiratory effort is of short duration relative to the preset inspiratory time, the ventilator switches back to volume control and the breath is volume cycled. The preset tidal volume is still delivered, but with a shorter inspiratory time, due to the increased average inspiratory flow. Because inspiration is again machine cycled, this type of breath is also mandatory. But if the patient makes a large enough inspiratory effort that lasts beyond the preset inspiratory time, the ventilator remains in pressure control and the breath is flow (ie, patient) cycled. If the breath was also patient triggered, it is virtually identical to a breath in the Pressure Support mode and as such is a spontaneous breath. ${ }^{10}$

From this analysis we see the possibility of spontaneous breaths occurring between mandatory breaths, and we conclude the breath sequence is intermittent mandatory ventilation. Finally, as just described, the targeting scheme is dual and we classify the mode as volume control intermittent mandatory ventilation with dual targeting for both primary and secondary breaths (VCIMVd,d). In passing, we note that pressure control with dual targeting is also possible, whereby inspiration starts out in pressure control but switches to volume control if the ventilator decides the preset tidal volume will not be delivered before inspiration cycles off. This was originally named Volume Assured Pressure Support. ${ }^{11}$

Table 1 shows how to classify several of the many noninvasive modes, and Table 2 applies the taxonomy to common invasive modes.

In conclusion, the classification of modes of mechanical ventilation is complex enough to require the full application of the tools for building a formal taxonomy, including both a controlled vocabulary and a hierarchical structure of key classification terms. Both the vocabulary and the hierarchy can be developed from the logical progression of 10 simple constructs that are familiar to stakeholders, including clinicians, educators, researchers, and manufacturers. ${ }^{1,5}$ While there may be any number of ways to create such a taxonomy, this one emphasizes the key factors that are important for clinicians to understand in order to optimize the match between the patient's needs and the ventilator's technological capabilities. ${ }^{6}$

\section{Abbreviated Controlled Vocabulary for Mechanical Ventilation}

\section{Adaptive Targeting Scheme}

A control system that allows the ventilator to automatically set some (or conceivably all) of the targets between breaths in response to varying patient conditions. One common example is adaptive pressure targeting (eg, Pressure Regulated Volume Control mode on the Maquet Servo-i ventilator) where a static inspiratory pressure is targeted within a breath (ie, pressure-controlled inspiration) but this target is automatically adjusted by the ventilator between breaths to achieve an operator set tidal volume target.

\section{Assisted Breath}

A breath during which all or part of inspiratory (or expiratory) flow is generated by the ventilator, doing work on the patient. In simple terms, if the airway pressure rises above end-expiratory pressure during inspiration, the breath is assisted (as in the Pressure Support mode). It is also possible to assist expiration by dropping airway pressure below end-expiratory pressure (such as Automatic Tube Compensation on the Dräger Evita 4 ventilator). In contrast, spontaneous breaths during CPAP are unassisted 
Table 1. Simplified Taxonomy for Classifying Modes for Noninvasive Ventilation

\begin{tabular}{|c|c|c|c|c|c|}
\hline $\begin{array}{l}\text { Order } \\
\text { Control } \\
\text { Variable }\end{array}$ & $\begin{array}{c}\text { Family } \\
\text { Breath Sequence }\end{array}$ & $\begin{array}{c}\stackrel{\text { Genus }}{\text { Primary Breath }} \\
\text { Targeting Scheme }\end{array}$ & $\begin{array}{c}\text { Species } \\
\text { Secondary Breath } \\
\text { Targeting Scheme }\end{array}$ & Example Mode Names & Tag \\
\hline \multirow[t]{2}{*}{ Volume } & CMV & Set-point & NA & Volume Controlled Ventilation & VC-CMVs \\
\hline & & Set-point & NA & Volume Assist/Controlled Ventilation & VC-CMVs \\
\hline \multirow[t]{8}{*}{ Pressure } & CMV & Set-point & NA & Pressure Control Ventilation & PC-CMVs \\
\hline & & Set-point & NA & Pressure Assist/Control Ventilation & PC-CMVs \\
\hline & & Adaptive & NA & Pressure Assist/Control Ventilation with Volume Targeting & PC-CMVa \\
\hline & IMV & Set-point & Set-point & Spontaneous/Timed & PC-IMVs,s \\
\hline & & Adaptive & Adaptive & Intelligent Volume Assured Pressure Support & PC-IMVa,a \\
\hline & & Adaptive & Adaptive & Average Volume Assured Pressure Support & PC-IMVa,a \\
\hline & CSV & Set-point & NA & Pressure Support & PC-CSVs \\
\hline & & Servo & NA & Proportional Pressure Ventilation & PC-CSVr \\
\hline $\begin{array}{l}\mathrm{CMV}=\text { cont } \\
\mathrm{NA}=\text { not ap } \\
\mathrm{VC}=\text { volum } \\
\mathrm{s}=\text { set-point } \\
\mathrm{PC}=\text { pressu } \\
\mathrm{a}=\text { adaptive } \\
\mathrm{IMV}=\text { inter } \\
\mathrm{CSV}=\text { conti } \\
\mathrm{r}=\text { servo }\end{array}$ & $\begin{array}{l}\text { uous mandatory ventilati } \\
\text { icable } \\
\text { control } \\
\text { control } \\
\text { ittent mandatory ventilati } \\
\text { ous spontaneous ventilat }\end{array}$ & & & & \\
\hline
\end{tabular}

because the ventilator attempts to maintain a constant airway pressure during inspiration.

\section{Bio-variable Targeting Scheme}

A control system that allows the ventilator to automatically set the inspiratory pressure or tidal volume randomly to mimic the variability observed during normal breathing.

\section{Breath}

A positive change in airway flow (inspiration) paired with a negative change in airway flow (expiration), associated with ventilation of the lungs. This definition excludes flow changes caused by hiccups or cardiogenic oscillations. However, it allows the superimposition of, for example, a spontaneous breath on a mandatory breath or vice versa. The flows are paired by size, not necessarily by timing. For example, in Airway Pressure Release Ventilation there is a large inspiration (transition from low pressure to high pressure), possibly followed by a few small inspirations and expirations, followed finally by a large expiration (transition from high pressure to low pressure). These compose several small spontaneous breaths superimposed on one large mandatory breath. In contrast, during High Frequency Oscillatory Ventilation, small mandatory breaths are superimposed on larger spontaneous breaths.

\section{Breath Sequence}

A particular pattern of spontaneous and/or mandatory breaths. The 3 possible breath sequences are: continuous mandatory ventilation (CMV), intermittent mandatory ventilation (IMV), and continuous spontaneous ventilation (CSV).

\section{CMV}

Continuous mandatory ventilation (commonly known as "Assist/Control"). A breath sequence in which mandatory breaths are delivered at a preset rate and spontaneous breaths are not possible between mandatory breaths. Patient-triggered mandatory breaths may occur between machine-triggered breaths (ie, the actual frequency may be higher than the set frequency). In some pressure-controlled modes on ventilators with an active exhalation valve, spontaneous breaths may occur during mandatory breaths, but the defining characteristic of CMV is that spontaneous breaths are not permitted between mandatory breaths, because an inspiratory effort after a mandatory breath triggers another mandatory breath.

\section{Control Variable}

The variable (ie, pressure or volume in the equation of motion) that the ventilator uses as a feedback signal to manipulate inspiration. For simple set point control, the control variable can be identified as follows:
If the peak inspiratory pressure remains constant as the load experienced by the ventilator changes, then the control variable is pressure. If the peak pressure changes as the load changes but tidal volume remains constant, then the control variable is volume. Volume control implies flow control and vice versa, but it is possible to distinguish the two on the basis of which signal is used for feedback control. Some primitive ventilators cannot maintain either constant peak pressure or tidal volume and thus control only inspiratory and expiratory times (ie, they may be called time controllers).

\section{CSV}

Continuous spontaneous ventilation. A breath sequence in which all breaths are spontaneous.

\section{Cycle Variable}

The variable (usually pressure, volume, flow, or time) that is used to end inspiration (and begin expiratory flow).

\section{Cycle (Cycling)}

To end the inspiratory time (and begin expiratory flow)

\section{Dual Targeting Scheme}

A control system that allows the ventilator to switch between volume control and pressure control during a single inspiration. Dual targeting is a more advanced version of set-point targeting. It gives the ventilator the decision of whether the breath will be 
Table 2. Simplified Taxonomy for Classifying Modes for Intensive Care

\begin{tabular}{|c|c|c|c|c|c|}
\hline $\begin{array}{l}\text { Order } \\
\text { Control } \\
\text { Variable }\end{array}$ & $\begin{array}{l}\text { Family } \\
\text { Breath Sequence }\end{array}$ & $\begin{array}{l}\text { Genus } \\
\text { Primary Breath } \\
\text { Targeting Scheme }\end{array}$ & $\begin{array}{l}\quad \underline{\text { Species }} \\
\text { Secondary Breath } \\
\text { Targeting Scheme }\end{array}$ & Example Mode Names & Tag \\
\hline \multirow[t]{7}{*}{ Volume } & CMV & Set-point & NA & Assist/Control Volume Control & VC-CMVs \\
\hline & & Dual & NA & $\begin{array}{l}\text { Continuous Mandatory Ventilation with } \\
\text { Pressure Limited }\end{array}$ & VC-CMVd \\
\hline & IMV & Set-point & Set-point & $\begin{array}{l}\text { Volume Control Synchronized } \\
\text { Intermittent Mandatory Ventilation }\end{array}$ & VC-IMVs,s \\
\hline & & Dual & Dual & Volume Control $^{*}$ & VC-IMVd,d \\
\hline & & Dual/Adaptive & Set-point & $\begin{array}{l}\text { Mandatory Minute Volume with } \\
\text { Pressure Limited Ventilation }\end{array}$ & VC-IMVda,s \\
\hline & & Dual & Adaptive & $\begin{array}{l}\text { Automode (Volume Control to Volume } \\
\text { Support) }\end{array}$ & VC-IMVd,a \\
\hline & & Adaptive & Set-point & Mandatory Minute Volume Ventilation & VC-IMVa,s \\
\hline \multirow[t]{13}{*}{ Pressure } & CMV & Set-point & NA & Pressure Control Assist Control & PC-CMVs \\
\hline & & Adaptive & NA & Pressure Regulated Volume Control & PC-CMVa \\
\hline & IMV & Set-point & Set-point & Airway Pressure Release Ventilation & PC-IMVs,s \\
\hline & & Adaptive & Set-point & $\begin{array}{l}\text { Adaptive Pressure Ventilation } \\
\text { Synchronized Intermittent Mandatory } \\
\text { Ventilation }\end{array}$ & PC-IMVa,s \\
\hline & & Adaptive & Adaptive & $\begin{array}{l}\text { Automode (Pressure Regulated Volume } \\
\text { Control to Volume Support) }\end{array}$ & PC-IMVa,a \\
\hline & & Optimal & Optimal & Adaptive Support Ventilation & PC-IMVo,o \\
\hline & & Optimal/Intelligent & Optimal/Intelligent & IntelliVent-ASV & PC-IMVoi,oi \\
\hline & CSV & Set-point & NA & Pressure Support & PC-CSVs \\
\hline & & Servo & NA & Proportional Assist Ventilation & PC-CSVr \\
\hline & & Servo & NA & Neurally Adjusted Ventilatory Support & PC-CSVr \\
\hline & & Adaptive & NA & Volume Support & PC-CSVa \\
\hline & & Adaptive & NA & Mandatory Rate Ventilation & PC-CSVa \\
\hline & & Intelligent & NA & SmartCare/PS & PC-CSVi \\
\hline $\begin{array}{l}\text { * Servo-i ven } \\
\text { CMV = cont } \\
\text { NA = not ap } \\
\text { VC }=\text { volum } \\
\mathrm{s}=\text { set-point } \\
\mathrm{d}=\text { dual } \\
\text { IMV }=\text { interı } \\
\mathrm{a}=\text { adaptive } \\
\text { PC }=\text { pressur } \\
\mathrm{o}=\text { optimal } \\
\mathrm{CSV}=\text { conti } \\
\mathrm{r}=\text { servo } \\
\mathrm{i}=\text { intelligen }\end{array}$ & $\begin{array}{l}\text { te } \\
\text { trol } \\
\text { trol mandatory ventilation } \\
\text { spontaneous ventilation. }\end{array}$ & & & & \\
\hline
\end{tabular}

volume or pressure-controlled, according to the operator set priorities. The breath may start out in pressure control and automatically switch to volume control, as in the Bird "VAPS" mode or, the reverse, as in the Dräger "Pmax" mode. The Maquet Servo-i ventilator has a mode called "Volume Control" and the operator presets both inspiratory time and tidal volume, as would be expected with any conventional volume control mode. However, if the patient makes an inspiratory effort that decreases inspiratory pressure by $3 \mathrm{~cm} \mathrm{H}_{2} \mathrm{O}$, the ventilator switches to pressure control, and, if the ef- fort lasts long enough, flow cycles the breath. Indeed, if the tidal volume and inspiratory time are set relatively low and the inspiratory effort is relatively large, the resultant breath delivery is indistinguishable from Pressure Support. As a result, the tidal volume may be much larger than the expected, preset value. This highlights the need to understand dual targeting. Because both pressure and volume may be the control variables during dual targeting, by convention we designate the control variable as the one with which the breath initiates. This is because the other control variable may never be implemented during the breath, depending on the other factors in the targeting scheme.

\section{Dynamic Compliance}

The slope of the pressure-volume curve drawn between two points of zero flow (eg, at the start and end of inspiration).

\section{Dynamic Hyperinflation}

The increase in lung volume that occurs whenever insufficient exhalation time prevents the respiratory system from returning to its normal resting end-expiratory equilibrium volume between breath cycles. Inappropriate operator set expiratory time may 
lead to dynamic hyperinflation, inability of the patient to trigger breaths, and an increased work of breathing.

\section{Elastance}

A mechanical property of a structure such as the respiratory system; a parameter of a lung model, or setting of a lung simulator; defined as the ratio of the change in the pressure difference across the system to the associated change in volume. Elastance is the reciprocal of compliance.

Equation of Motion for the Respiratory System

A relation among pressure difference, volume, and flow (as variable functions of time) that describes the mechanics of the respiratory system. The simplest and most useful form is a differential equation with constant coefficients describing the respiratory system as a single deformable compartment including the lungs and chest wall:

$\Delta \mathrm{P}_{\mathrm{TR}}(\mathrm{t})+\Delta \mathrm{P}_{\text {mus }}(\mathrm{t})=\mathrm{EV}(\mathrm{t})+\mathrm{RV}(\mathrm{t})+$ autoPEEP

\section{where}

$\Delta \mathrm{P}_{\mathrm{TR}}(\mathrm{t})=$ the change in transrespiratory pressure difference (ie, airway opening pressure minus body surface pressure) as a function of time $(\mathrm{t})$, measured relative to endexpiratory airway pressure. This is the pressure generated by a ventilator $\left(\Delta \mathrm{P}_{\text {vent }}\right)$ during an assisted breath.

$\Delta \mathrm{P}_{\text {mus }}(\mathrm{t})=$ ventilatory muscle pressure difference as a function of time $(\mathrm{t})$; the theoretical chest wall transmural pressure difference that would produce movements identical to those produced by the ventilatory muscles during breathing maneuvers (positive during inspiratory effort, negative during expiratory effort)

$\mathrm{E}=$ elastance (inverse of compliance; $\mathrm{E}=1 / \mathrm{C})$

$\mathrm{V}(\mathrm{t})=$ volume change relative to endexpiratory volume as a function of time $(t)$

$\dot{\mathrm{V}}(\mathrm{t})=$ flow as a function of time $(\mathrm{t})$, the first derivative of volume with respect to time

autoPEEP = end-expiratory alveolar pressure above end-expiratory airway pressure

For the purposes of classifying modes of mechanical ventilation the equation is often simplified to:

$$
\begin{aligned}
& \mathrm{P}_{\text {vent }}=\mathrm{EV}+\mathrm{RV} \\
& \text { where } \\
& \mathrm{P}_{\text {vent }}=\text { the transrespiratory pressure dif- }
\end{aligned}
$$
ference (ie, "airway pressure") generated by the ventilator during an assisted breath

\section{Feedback Control}

Closed loop control accomplished by using the output as a signal that is fed back (compared) to the operator-set input. The difference between the two is used to drive the system toward the desired output (ie, negative feedback control). For example, pressure-controlled modes use airway pressure as the feedback signal to manipulate gas flow from the ventilator to maintain an inspiratory pressure set-point.

\section{Flow Control}

Maintenance of an invariant inspiratory flow waveform despite changing respiratory system mechanics

\section{Flow Triggering}

The starting of inspiratory flow due to a patient inspiratory effort that generates inspiratory flow above a preset threshold (ie, the trigger sensitivity setting)

\section{Flow Target}

Inspiratory flow reaches a preset value that may be maintained before inspiration cycles off.

\section{Flow Cycling}

The ending of inspiratory time due to inspiratory flow decay below a preset threshold (also known as the cycle sensitivity).

Intermittent Mandatory Ventilation

Breath sequence in which spontaneous breaths are permitted between mandatory breaths. For most ventilators, a short "window" is opened before the scheduled machine triggering of mandatory breaths, to allow synchronization with any detected inspiratory effort on the part of the patient. This is referred to as synchronized IMV (or SIMV). Three common variations of IMV are: mandatory breaths are always delivered at the set frequency; mandatory breaths are delivered only when the spontaneous breath frequency falls below the set frequency; mandatory breaths are delivered only when the spontaneous minute ventilation (ie, product of spontaneous breath frequency and spontaneous breath tidal volume) drops below a preset or computed threshold (also known as Mandatory Minute Ventilation).

For some modes (eg, Airway Pressure Release Ventilation), a short window is also opened at the end of the inspiratory time. Because spontaneous breaths are allowed during the mandatory pressure controlled breath, this window synchronizes the end of the mandatory inspiratory time with the start of spontaneous expiratory flow, if detected. With these technological developments, potential confusion arises as to whether inspiration that is synchronized (either start or stop) is considered patient triggered/cycled or machine triggered/cycled. If we say synchronized breaths are patient triggered and cycled, we have the awkward possibility of a spontaneous breath occurring during another spontaneous breath. This is avoided by distinguishing between a trigger window and a synchronization window.

There are some modes where the idea of IMV may be vague: with Airway Pressure Release Ventilation, relatively high frequency spontaneous breaths are superimposed on low frequency mandatory breaths. However, the expiratory time between mandatory breaths is often set so short that a spontaneous breath is unlikely to occur between them. Other ambiguous modes are High Frequency Oscillation, High Frequency Jet Ventilation, Interpulmonary Percussive Ventilation, and Volumetric Diffusive Respiration. With these modes, high frequency mandatory breaths are superimposed on low frequency spontaneous breaths and, again, there is no possibility of a spontaneous breath actually occurring between mandatory breaths. Nevertheless, we classify all these modes as forms of IMV because spontaneous breaths can occur along with mandatory breaths and because spontaneous efforts do not affect the mandatory breath frequency. See machine triggering, patient triggering, synchronization window, and trigger window.

\section{Inspiratory Pressure}

General term for the pressure at the patient connection during the inspiratory phase. For pressure control modes, where the inspiratory pressure is targeted to a preset value, the term is used to designate this setting. If inspiratory pressure is set relative to atmospheric pressure, the term "peak inspiratory pressure" is used. If inspiratory pressure is set relative to PEEP, the term "inspiratory pressure" is used.

\section{Intelligent Control}

A ventilator control system that uses artificial intelligence programs such as fuzzy logic, rule based expert systems, and artificial neural networks. One example is the rule based system used by SmartCare (Dräger Evita XL ventilator).

\section{Machine Cycling}

Ending inspiratory time independent of signals representing the patient determined components of the equation of motion (ie, $\mathrm{P}_{\text {mus }}$ [effort], elastance, or resistance). Common examples of machine cycling variables are preset inspiratory time and tidal volume. 


\section{Machine Triggering}

Starting inspiratory flow based on a signal (usually time) from the machine, independent of a signal indicating patient inspiratory effort. Examples include triggering based on a preset frequency (which sets the ventilatory period), or based on a preset minimum minute ventilation (determined by tidal volume divided by the ventilatory period). If a signal from the patient (indicating the need for inspiration) occurs within a synchronization window, the start of inspiration is defined as a machine trigger event that begins a mandatory breath. See intermittent mandatory ventilation, patient triggering, synchronization window, and trigger window.

\section{Mandatory Breath}

A breath in which the patient has lost substantial control over timing. This means a breath in which the start or end of inspiration (or both) is determined by the ventilator, independent of the patient. That is, the machine triggers and/or cycles the breath.

\section{Mechanical Ventilator}

An automatic machine designed to provide all or part of the work required to generate enough breaths to satisfy the body's respiratory needs.

\section{Mode of Ventilation}

A predetermined pattern of interaction between a patient and a ventilator, specified as a particular combination of control variable, breath sequence, and targeting schemes for primary and secondary breaths.

\section{Optimum Targeting Scheme}

A ventilator control system that automatically adjusts the targets of the ventilatory pattern to either minimize or maximize some overall performance characteristic. One example is Adaptive Support Ventilation (Hamilton Medical G5 ventilator), in which the ventilator adjusts the mandatory tidal volume and frequency (for a passive patient) in such a way as to minimize the work rate of ventilation.

\section{Patient Cycling}

Ending inspiratory time based on signals related to one of the patient determined components of the equation of motion (ie, $\mathrm{P}_{\text {mus }}$ [effort], elastance, or resistance). Common examples of cycling variables are peak inspiratory pressure and percent inspiratory flow.

\section{Patient Triggering}

Starting inspiratory flow based on signals representing the patient determined components of the equation of motion (ie, $\mathrm{P}_{\text {mus }}$ [effort], elastance, or resistance). Com- mon examples of patient trigger variables are airway pressure drop below baseline and inspiratory flow due to patient effort.

\section{PC-CMV}

Pressure-controlled continuous mandatory ventilation

\section{PC-IMV}

Pressure-controlled intermittent mandatory ventilation

\section{PC-CSV}

Pressure-controlled continuous spontaneous ventilation

\section{Pressure Control}

A general category of ventilator modes in which pressure delivery is predetermined by a targeting scheme such that inspiratory pressure is either proportional to patient effort or has a particular waveform, regardless of respiratory system mechanics.

\section{Pressure Cycling}

Inspiratory time ends when airway pressure reaches a preset threshold.

\section{Pressure Triggering}

The starting of inspiratory flow due to a patient inspiratory effort that generates an airway pressure drop below end-expiratory pressure larger than a preset threshold (ie, the trigger sensitivity setting).

\section{Pressure Target}

Inspiratory pressure reaches a preset value before inspiration cycles off.

\section{Primary Breaths}

Mandatory breaths during CMV or IMV, or spontaneous breaths during CSV.

\section{Secondary Breaths}

Spontaneous breaths during IMV.

\section{Servo Targeting}

A control system in which the output of the ventilator automatically follows a varying input. For example, the Automatic Tube Compensation feature on the Dräger Evita 4 ventilator tracks flow and forces pressure to be equal to flow multiplied by a constant (representing endotracheal tube resistance). Other examples include Proportional Assist Ventilation (Covidien Puritan Bennett 840 ventilator; pressure is proportional to spontaneous volume and flow) and Neurally Adjusted Ventilatory Assist (Maquet Servo-i ventilator; pressure is proportional to diaphragmatic electrical activity). For all 3 of these example modes, airway pressure is effectively proportional to the patient's inspiratory effort.

\section{Set-Point Targeting}

A control system in which the operator sets all the parameters of the pressure waveform (pressure control modes) or volume and flow waveforms (volume control modes).

\section{Spontaneous Breath}

A breath in which the patient retains substantial control over timing. This means the start and end of inspiration may be determined by the patient, independent of any machine settings for inspiratory time and expiratory time. That is, the patient both triggers and cycles the breath. Note that use of this definition for determining the breath sequence (ie, CMV, IMV, CSV) assumes normal ventilator operation. For example, coughing during VC-CMV may result in patient cycling for a patient-triggered breath, due to the pressure alarm limit. While inspiration for that breath is both patient-triggered and patient-cycled, this is not normal operation and the sequence does not turn into IMV.

\section{Synchronized IMV (SIMV)}

A form of IMV in which mandatory breath delivery is coordinated with patient effort. A synchronized breath is considered to be machine triggered.

\section{Synchronization Window}

A short period at the end of the expiratory time (eg, based on a preset mandatory breath frequency and inspiratory time) or at the end of a preset inspiratory time, during which a patient signal may be used to synchronize flow to patient effort. If a signal from the patient (indicating the need for inspiration) occurs during the expiratory time within the window, inspiration starts and is defined as a machine triggered event that begins a mandatory breath. This is because the mandatory breath would have been time triggered regardless of whether the patient signal had appeared or not, and because the distinction is necessary to avoid logical inconsistencies in defining mandatory and spontaneous breaths, which are the foundation of a mode taxonomy. Sometimes a synchronization window is used at the end of a pressure controlled, time cycled breath. For example, during Airway Pressure Release Ventilation the patient is free to take spontaneous breaths during a mandatory breath. If a signal from the patient (eg, the start of expiratory flow for a spontaneous breath) occurs during the inspiratory time within the window, inspiration stops and is defined as a machine cycled event that ends a mandatory breath. See intermittent mandatory ventilation, machine triggering, patient triggering, trigger window. 


\section{Target}

A predetermined goal of ventilator output. Targets can be viewed as the parameters of the targeting scheme. Within-breath targets are the parameters of the pressure, volume, or flow waveform. Examples of within-breath targets include inspiratory flow or pressure rise time (set-point targeting), inspiratory pressure, tidal volume (dual targeting), and the constant of proportionality between inspiratory pressure and patient effort (servo targeting). Between-breath targets serve to modify the within-breath targets and/or the overall ventilatory pattern. Between-breath targets are used with more advanced targeting schemes, where targets act over multiple breaths. A simple example of a between-breath target is to compare actual exhaled volume to a preset between-breath tidal volume in order to automatically adjust the within-breath inspiratory pressure or flow target for the next breath. Examples of between-breath targets and targeting schemes include average tidal volume (for adaptive targeting), percent minute ventilation (for optimal targeting), and combined $\mathrm{P}_{\mathrm{CO} 2}$, volume, and frequency values describing a "zone of comfort" (for intelligent targeting).

\section{Targeting Scheme}

A model of the relationship between operator inputs and ventilator outputs to achieve a specific ventilatory pattern, usually in the form of a feedback control system. The targeting scheme is a key component of a mode description.

\section{Time Cycling}

Inspiratory time ends after a preset time interval has elapsed. The most common examples are a preset inspiratory time or a preset inspiratory pause time.

\section{Time Triggering}

The starting of inspiratory flow due to a preset time interval. The most common example is a preset ventilatory frequency.

\section{Trigger Window}

The period composed of the expiratory time (minus a short "refractory" period required to reduce the risk of triggering a breath before exhalation is complete). If a signal from the patient (indicating the need for inspiration) occurs within this trigger window, inspiration starts and is defined as a patient triggered event. See intermittent mandatory ventilation, machine triggering, pa- tient triggering, and synchronization window.

Trigger (Triggering)

To start inspiration. See machine triggering, patient triggering.

Ventilatory Pattern

A sequence of breaths (CMV, IMV, or CSV) with a designated control variable (volume, pressure, or dual control) for the mandatory breaths (or the spontaneous breaths for CSV)

\section{Volume Control}

A general category of ventilator modes in which both inspiratory flow and volume delivery are predetermined by a targeting scheme to have particular waveforms independent of respiratory system mechanics. Usually, flow and tidal volume may be set directly by the operator. Alternatively, the ventilator may determine tidal volume based on operator preset values for frequency and minute ventilation, or the ventilator may determine inspiratory flow based on operator set tidal volume and inspiratory time. Note that the tidal volume setting refers to the within-breath tidal volume, not a betweenbreath target as used in adaptive pressure targeting (see adaptive targeting scheme).

\section{VC-CMV}

Volume-controlled continuous mandatory ventilation

\section{VC-IMV}

Volume-controlled intermittent mandatory ventilation

\section{Volume Triggering}

The starting of inspiratory flow due to a patient inspiratory effort that generates an inspiratory volume signal larger than a preset threshold (ie, the trigger sensitivity setting)

\section{Volume Target}

A preset value for tidal volume that the ventilator is set to attain either within a breath or as an average over multiple breaths.

\section{Volume Cycling}

Inspiratory time ends when inspiratory volume reaches a preset threshold (ie, tidal volume).

\section{REFERENCES}

1. Chatburn RL, Volsko TA, Hazy J, Harris LN, Sanders S. Determining the basis for a taxonomy of mechanical ventilation. Respir Care 2012;57:514-24.
2. Hedden, H. The accidental taxonomist. Medford, NJ: Information Today, 2010.

3. Cowan N. The magical number 4 in shortterm memory: a reconsideration of mental storage capacity. Behav Brain Sci 2001; 24(1):87-114, discussion 114-185.

4. Bailey KD. Typologies and taxonomies: an introduction to classification techniques. Thousand Oaks, London: Sage Publications; 1994.

5. Chatburn RL. Classification of mechanical ventilators and modes of ventilation. In: Tobin MJ, ed. Principles and practice of mechanical ventilation, 3rd edition. New York: McGraw-Hill; 2012.

6. Mireles-Cabodevila E, Hatipoglu U, Chatburn RL. A rational framework for selecting modes of ventilation. Respir Care 2012. Epub ahead of print.

7. Chatburn RL, Mireles-Cabodevila E. Closed-loop control of mechanical ventilation: description and classification of targeting schemes. Respir Care 2011;56(1): 85-102.

8. Guskey TR. Closing achievement gaps: revisiting Benjamin S Bloom's "learning for mastery." J Advanced Academics 2007; 19(1):8-31.

9. McGaghie WC, Issenberg B, Cohen ER, Barsuk JH, Wayne DB. Medical education featuring mastery learning with deliberate practice can lead to better health for individuals and populations. Academic Med 2011;86(11):e8-e9.

10. Volsko TA, Hoffman J, Conger A, Chatburn RL. The effect of targeting scheme on tidal volume delivery during volume control mechanical ventilation. Respir Care 2012;57(8):1297-1304.

11. Amato MB, Barbas CS, Bonassa J, Saldiva $\mathrm{PH}$, Zin WA, de Carvalho CR. Volumeassured pressure support ventilation (VAPSV): a new approach for reducing muscle workload during acute respiratory failure. Chest 1992;102(4):1225-1234.

\section{Robert L Chatburn MHHS RRT-NPS}

FAARC

Respiratory Institute The Cleveland Clinic Cleveland, Ohio

Mr Chatburn has disclosed relationships with the Alpha-1 Antitrypsin Foundation, Breathe Technologies, CareFusion, Covidien, Dräger, Hamilton, IngMar, Newport, Philips, Radiometer America, ResMed, Respironics, Strategic Dynamics, and Teleflex.

DOI: $10.4187 /$ respcare. 02122 